\title{
New Families, New Texts: An Exploration of Viewing, Text, and Schooling from the Perspective of Being an "Other Kind of Family"
}

\author{
LINDA LAIDLAW \\ University of Alberta
}

...the nuclear family has, since the mid-twentieth century, been constructed as the natural social form in western epistemology and has informed much of the theorizing of the family in the West.... It has become a normative narrative against which others, and ourselves, have been measured. (Carrington, 2002, p. 17)

My family is different. Not by any stretch of the imagination do we fit into the "normative narrative" Carrington (2002) describes, nor do we fit into the "severely normal" category described by former Alberta premier Ralph Klein, in reference to the typical Alberta family. I adopted my daughters as a single parent, as a third generation Canadian woman of mixed European and British ancestry, living in a Canadian province where relatively few singles adopt, a place that has been publicly known for being less tolerant of difference (Filax, 2002), and where, more recently, Bill 44 has been passed, allowing parents to have their children opt out (and be notified in advance) of any classroom discussions involving religion, sexual orientation, and sexuality, said to be supported by "severely normal Albertans" (see CBC News, 2009).

My daughters are Chinese, one from the south of China and one from a northern Chinese province bordering on Tibet. One adoption is likely related to China's one child policy and the second likely due to lack of cultural acceptance of visible, physical differences - my younger child has a condition sometimes known as ectrodactly, a genetic issue that affects the structure of her hands and feet. While I never intended for us to be the poster family for diversity, it seems that we cover a number of different categories: single parent, adoptive, transracial, limb differences, and working academic parent. We attract attention as a family, something that can still surprise me until I remember that we do not much resemble the typical family who might enter a library or school or grocery store.

As a literacy researcher and someone with deep interest in the texts available to children-including picture books, school related texts, and media and electronic texts - my membership in a diverse family structure has caused me to pay more attention to what my children notice in the world around them, and specifically whether they recognize themselves as in any way reflected in the texts they encounter. ${ }^{1}$ I have also queried, through a recent research project, the experiences of a group of diverse adoptive families (SSHRC \# G124130428 Changing Families, Changing Schools: A Study of International Adoption and Normative Structures in Education). Within a survey undertaken in the initial phase of the study, participants frequently made comments in relation to the sorts of texts or resources that were available (or not) in their children's schools. While the surveys addressed broader topics of identity, schooling, and 
curriculum, parent responses frequently discussed issues and situations directly linked to language and literacy instruction, and it is primarily these responses that this article will address. $^{2}$

Using both autobiographical experiences and data from the research surveys, I will explore the problems presented when children do not see themselves in the texts around them, including the texts offered by curriculum, as well as how old and new literacies can offer possibilities for children of new families in and out of school. As adoption educators Wood and $\mathrm{Ng}$ (2001) suggest, "All children learn when all families are respected" (p. 76). I would suggest, too, that all children learn when they see a wide array of diversity in the texts that form the backdrop of their literacy experiences at school.

I am following the path of literacy researchers and theorists who have argued that school literacy experiences, as social and cultural phenomena, do not meet the needs of all children. Heath $(1983,1982)$, in her well known ethnographic research, queries the mismatch of school-based literacy with the literacies and oral language practices occurring in the working class homes of her study. Carrington and Luke (2003) make the case for understanding language and literacy as being altered by "new economic, social, and cultural conditions" (p. 231) that have shifted definitions of family and of the literacies occurring in children's homes. They state: "New family formations, new literacies and technologies, then, are volatile and potentially disruptive of the longstanding "rules of the game" for literacy teaching and learning" (p. 248). As Diaz and Makin (2002) suggest, school programs become less effective when some children are marginalized and their home experiences ignored. The curriculum, activities, materials, and resources present in language arts classrooms convey cultural models (Gee, 2001) that provide tacit representations about what is regarded as normal and what is not.

The variety of texts that children view or interact with, of course, are not limited to school, and whether or not those "outside of school texts" are recognized, they too influence how adopted children see themselves reflected in the world at large and may also influence society's views about adoption and adoptees. Thus, I will begin by sharing observations I have made over the past few years as my daughters each became interested in "Elmo's World" videos (Elmo's World, 2004) and the collection of Sesame Street Programs. ${ }^{3}$ What soon became interesting to me was at that point in our viewing of different television shows intended for the very young, Elmo's World, ${ }^{4}$ featured within Sesame Street programming, seemed to be one of few consistent examples of children's media that actively and visibly represented families that were somewhat like ours, families that diverged in multiple ways from the traditional or nuclear normative family structure.

While Elmo's World videos or clips do feature normative two parent family models and these examples are frequently placed in the foreground, other family structures also populate examples as well as being featured in various short clips throughout the Elmo series. Typical of all Sesame Street programming, the overall picture is one of diversity in many respects: race, family formation, and physical or ability differences. All kinds of families are indeed represented - single parent and same sex families, transracial families (including those who appear to be adoptive families, for example, one clip shows a White mother taking her Asian child to see a dinosaur display), families from a wide range of cultures, ethnicities, and featuring children who show a 
wide range of diversity in abilities (e.g. a deaf child and his friend on a play date, a dancing child in a wheelchair, a child with Down's syndrome going swimming). Importantly, these families and individuals are generally not presented as lessons on diversity, as happens in some children's programming, but rather, as part of the collection of all people presented within Sesame Street or Elmo's world, and as participants in regular activities such as play dates, dancing, swimming, going to museums.

When I returned to further viewing of Elmo and Sesame Street episodes while on parental leave after the adoption of my second daughter, I was interested to note a series of episodes depicting an adoption story similar to those of my own family. Gina, the Sesame Street veterinarian, adopts Marco, a toddler boy from Guatemala, as a single mom. A little digging, however, suggests that these episodes were not haphazard depictions, but were carefully crafted to reflect societal change:

Due to the increase in single-parent homes and multiracial families, Sesame Street decided to address single motherhood and multiracial adoption. In formative testing, children viewed an episode where Gina, a Caucasian single woman, adopts Marco, a Guatemalan baby. While few children understood the concept of adoption in pre-testing, in post-testing, 76\% understood Marco and Gina were a family. (Kotler, Cohen, \& Truglio, 2007, n.p.)

While for families like mine there is a sense of recognition and belonging in the world when we see families that resemble ours within popular media or the books and classroom materials that we encounter, the Sesame Street research points to an additional benefit: inclusion of diverse examples may also provide opportunities for all children to understand more about other kinds of families who may be different from their own. Providing explanation of our family formation and structure, dealing with ignorance or just too much benign curiosity tends to be an ongoing theme in my family's day-to-day life, as was similarly reported by the parents in my study. As one parent summarizes:

On some levels there are obvious differences in our family when we are compared to others - our children are of a different race [than we are] so we look different.... I have noticed that we are conspicuous in public. For example, when we go to a restaurant, I sometimes notice that we are "looked at" when we enter.

While the parents who responded to my qualitative survey live in different regions of Canada and in rural, suburban, and urban settings, all mentioned standing out to some extent due to their visibly different family form with some being an entirely "new" family structure in their area, and others having a few other transracial adoptive families nearby or groups of adoptive families who meet regularly within adoption related organizations. While families who reside in more urban communities typically saw their families as fitting into a broader multiethnic demographic, they still viewed the adoption aspect of their family formation as making them relatively distinct from most families. ${ }^{5}$

\section{A Few Words about Methodology}

As there has been little research inquiring into the schooling experiences of families formed by international adoption, my study was framed to survey a group of such parents, through the completion of written, open-ended qualitative surveys, with follow-up email and telephone exchanges to clarify and elicit further details and information. Alternately, several families chose to respond to the questions via an oral interview. Survey questions addressed four categories: questions about family identity 
and structure; general questions about schooling; more focused questions about schooling, curriculum, school resources and activities (e.g. What sort of books does your child have access to in the classroom or school library that address family or ethnic diversity? Have any particular school assignments or activities posed problems for your child? Were any particular school assignments or activities particularly valuable for your child?), and, finally, questions that asked parents for their thoughts and suggestions in regards to what they believed schools might change or improve to address the needs of children who are international adoptees. The last two question categories frequently elicited data connected to language and literacy structures and practices. The surveys and follow up questions, while mainly in written form, were intended to take an ethnographic approach, that is, as developed by others (Behar, 1996; Clifford \& Marcus, 1986; Geertz, 1988; Richardson, 1997) as research opportunities where both participant and researcher are acknowledged as involved in multiple layers of cultural experience and biographical positioning.

Participating families came from three regions in Canada: Western Canada (5 participants), Atlantic Canada (2 participants), and 10 participants in Central Canada within the province of Ontario. The majority of families had daughters who were adopted from China, but several children were adopted from Korea, Vietnam, or Haiti. ${ }^{6}$ All of the children were in elementary school (preschool to grade six) at the time of the survey and interviews. All adoptive parents who responded to the survey were Euro-descent Canadians and included 2 Francophone Canadians (French Canadians living outside of Quebec) and one parent who had emigrated from Australia. ${ }^{7}$ Participants were recruited via advertising the project on a variety of electronic Canadian adoption discussion boards through Canadian international adoption agencies and adoption related associations.

I also initially considered interviewing some of the elementary school aged children, and received ethics approval to do so. However, as an adoptive parent myself and after engaging in informal insider conversations within my own local international adoption community, I became aware of more subtle ethical issues involved in asking younger transracially adopted children about their experiences of adoption and/or inclusion at school. I soon realized that such questions could sensitize them further to issues that they had not previously been aware of and may not have discussed with their families - for this reason, most of the families I spoke with in planning the parent surveys and interviews said while they would gladly participate themselves, they would be anxious about having their children participate. While I believe it would be valuable to gather children's perceptions and stories, I hope to pursue this missing piece in a future project with older adoptees. In spite of the absence of student voices, the stories shared by parents provide a good starting place in terms of providing new data in an area where little previous inquiry exists, in offering response to some commonplace language and literacy school assignments. However, I also acknowledge some limitations: parents may not always be fully aware of all experiences in their children's school lives, some parents may resist noticing difficulties experienced by their internationally adopted children (see, for example, Palmer, 2001), and children may sometimes keep negative experiences or interpretations (e.g. of school resources, books etc.) to themselves so as not to upset their parents. Based on these limitations I suspect that my survey and interview data provides an underrepresentation of the negative experiences of adoptees.

It is important to mention that while it is possible to collect data, develop statistics, and note trends in research such as this, my project has focused on gathering the small 
stories families recognize as significant. Like Behar (1996) I understand the "web of stories" that emerges as the individual stories are told communicates more than simple statistics do. Collectively, these stories provide insights into how families experience their differences and the ways in which particular practices in language arts classrooms can exclude their children.

In a study such as this it is important to provide the reader with some background reading for contextual understanding. The following section addresses how adoption and other social changes are being reflected within the make up of the Canadian family.

\section{New Families}

Mirroring North American trends (see Turner-Vorbeck, 2005), the composition of Canadian families has changed significantly in the past decade (see for example, Statistics Canada, 2002; Statistics Canada, 2006). Increasingly, contemporary families consist of a wide range of configurations, including blended families, common-law families, gay and lesbian families, single parent families (including an increase of those headed by males), and greater than ever diversity in racial and cultural heritage.

The emergence of families formed by adoption is not a particularly new part of the mix, with transracial adoption in Canada acknowledged as occurring since the 1950s (Simon \& Altstein, 2000). The nature of adoptive families has continued to evolve further since then, with growing participation of nontraditional families in adoption and with adoptive families increasingly diverse in ethnicity as well as in configuration (e.g., including more families where one or both partners are non-White, although some of these families may be adopting from a country of ancestry). With very few infants or toddlers available in domestic adoptions, families are choosing to adopt internationally as another option, often forming transracial and what I label "global family" structures, as families look to "sending countries" across the world, and even to multiple countries to add to their families (see Alberta Children's Services, 2008, for a sample of recent Alberta adoption statistics, and Hilborn, 2009, for a wider array of Canadian statistics). ${ }^{8}$

Although there are no available statistics in terms of family composition and ethnicity within adoptive families, general observations in regards to members of local, national, and international adoption groups suggest increased diversity in both those areas. As Pertman states (in Hunt, 2003):

adoptive families come in all kinds. Single-parent, gay and lesbian, multi-ethnic, blended. In fact, there's only one kind of family that adoptive families are not: the so-called typical family with their two parents and their two offspring. (p. 2)

Of course, the children from such "new families" are present in elementary language arts classrooms, although schools have not typically acknowledged such changes in family formation. These and other "new families" remain largely unrepresented. The modern nuclear, or "traditional" biological family is still the normative standard against which all other family models are measured, and where, in contrast, alternative family structures may be represented as deficient or illegitimate (Carrington, 2002; Carrington \& Luke, 2003; Patton, 2000). Similarly, within popular media aimed at children, Sesame Street aside, nontraditional families tend to be conspicuous by their absence, and attempts at representing diversity typically involve the creation of supporting characters who are non-White or have a disability, when diversity is attempted (e.g., children's television programs such as Caillou, Arthur, Martha Speaks, 
Clifford, Pinky Dinky Do, Jacob Two Two). Additionally, where popular children's series do feature major characters who are non-White (e.g. Dora, Diego, Little Bill), they are frequently presented as members of traditional biological families. As Turner-Vorbeck (2005a, cited in Turner-Vorbeck, 2005) states,

Most popular, top-selling children's books and related television series and movies....continue to feature portrayals of families in the literary and visual images of American child culture that still consist largely of traditional, two parent households with the mother fulfilling the role of primary nurturer and caregiver. (p. 10)

When my children and their peers from similarly diverse families look at the representations of families on television and at school, it is rare that they see themselves reflected back. Where they are more likely to find themselves is within new media such as online environments, in the blogs created by other adoptive families or their children, within adoption community discussion groups, Facebook pages, and on Youtube or other video media posted by families. As well, it is common for internationally adopted children to learn more about their cultural roots or their birth country via orphanage group websites, and other online resources. New media provide opportunities for internationally adopted children to find themselves in ways that print-based children's literature often does not (e.g., Satz, 2007).

\section{New Classrooms?}

My own and other Canadian faculties of education currently grapple with preparing new teachers for more diverse classrooms, and my language and literacy colleagues and I also attempt to address diversity issues within our courses. Often, however, consistent with Turner-Vorbeck's (2005) American research, when diversity is addressed in schools, issues of racial, ethnic, and cultural diversity tend to predominate. This approach was also reflected in what my parent participants reported in regards to the positive moves they saw schools making in terms of presenting or addressing diversity. Typical parent comments included the following observations of what was seen as representing diversity in their children's Canadian classrooms:

- Books, music, acknowledgment of religious celebrations,

- The books in her reading program represent many different ethnicities,

- Ethnic diversity is generally well represented in books and visual displays,

- Chinese New Year is one of the holidays addressed in the school curriculum,

- School year events and art displays encompass numerous cultures,

- Many of the books that come home from the school show children of different races.

Observations such as the ones above are consistent with what researchers affiliated with the Metropolis Project ("Policy-relevant Research on Immigration and Settlement," 2005) have noted in response to multicultural policies within Canadian education systems: "Despite the existence of these ... kinds of policies, most schools, with their limited resources, have had difficulty in going beyond shallow and static presentation of culture reduced to ethnic food, dress and quaint customs" (p. 1). While such policies are developed with the intention of promoting tolerance and inclusion within Canadian schools, the Metropolis researchers suggest that actual changes tend to be superficial. Similarly, one of the mothers in my study remarked on the simplicity of the efforts, when 
asked if she felt her child's ethnicity was adequately represented at school: "Definitely. Perhaps disproportionately because she is young and the concreteness of her physical experience makes it easy to share dragons and chopsticks with her classmates, which we actively facilitate." Examples of racial and cultural diversity are also evident in current language arts instructional series. However, the inclusion of books and celebrations that were mentioned by participants are also less likely to elicit any potentially troubling discussions that might emerge if deeper aspects of culture were addressed, such as those involving values systems, beliefs, and other aspects of living and evolving cultures. ${ }^{9}$

What the parents in my study consistently noted as a conspicuous absence in their children's schools was acknowledgement and inclusion of diversity of family formations. Parents commented on gaps in both curriculum and in materials, such as a lack of books on adoption in the school library or the classroom. Consistent with these parent observations, Gregory and Snow-Gerono's (2006) research studying diversity in classroom environments points out that few representations of diversity in family constructs were apparent in the US schools involved in their study. Supporting this findings are the following reflections provided by the parents in my study:

- It would be most helpful to think of inclusiveness in general and not just toward adoptive and transracial families.... There is a particular need in my daughter's school to talk about single-parent and same-sex families.

- I would hope that school boards and teacher education faculties could make a point of stressing awareness and sensitivity around adoption (and all kinds of family diversity, for that matter) for teachers, to avoid careless or hurtful assumptions or exclusions.

- I think resources (books, videos, guest speakers) which look at alternative types of families and ways of living are always beneficial for all children.

- Educate all students on different family compositions...

- I think that schools need to acknowledge that the traditional "family" (dad, mom and kid(s)) does not really exist anymore. You deal with divorce, live-ins, step parents, grandparents living in, single parents by choice, gay parents etc. What is a "typical" family?

If educators acknowledge the observations of parent participants and Gregory and Snow-Gerono (2006) as pointing to an "absence", why is it that schools do not seem to be addressing or representing alternate family structures, including those of adoption? Within a language arts classroom, for example, providing literature resources that include a variety of family structures would not require a monumental effort.

Conversations with both preservice and practicing teachers in relation to the data from my project seem to indicate that the first barrier may be a lack of awareness. When teachers work with children, family structure or birth history is not necessarily visible. While familial diversity has been discussed as an area needing to be addressed within my own teacher education faculty, to this point pre-service teachers do not consistently receive any required coursework that addresses the topic and so societal biases or assumptions about different kinds of families can remain unchallenged.

Such biases are also present in children's literature. Satz (2007) in her analysis of adoption images in children's fiction suggests that long held views of adoptive relationships as a "fictional facsimile" of biological relationships permeate many popular 
children's books. She presents a variety of examples of popular children's fictions, including Hans Christian Anderson's The Ugly Duckling, P.D. Eastman's Are You My Mother? and Janell Cannon's Stellaluna, where a character begins with those different from themselves as their family but by the end of the story, come to realize that their true home is with their own kind. Satz argues that such examples represent dominant societal views.

Several writers on adoption would argue that these belief structures stem from what they name as "genealogy ideology" or "genetic ideology" (e.g., Pertman, 2000; Rothman, 2005; Volkman, 2003). These notions filter into a variety of texts and media, as well as day-to-day discourse, including those encountered within the contexts of language arts classrooms and the texts children find on their classroom or library bookshelves. Put simply, this is the belief that everyone must have knowledge of their genetic history and genealogy in order to be complete even if these are not readily available:

In reality, of course, we are all unknown and unknowable. Which genes are inherited and which not.... But we are not talking about genetic science; we are talking about genetic ideology, the popular belief system that has grown up with, alongside, out of, and underpinning the genetic science. (Rothman, 2005, p. 61)

As Satz observes, in children's books such as The Ugly Duckling or Are You My Mother?, "if one is not among one's own one will suffer denigration and abuse" (p. 165). The implicit message of these and similar find your kind themed picture books or activities ${ }^{10}$ is that biological or matching families are best.

Several examples of troublesome language and literacy activities for adoptees that were shared by adoptive parents also seem to carry underlying genealogical assumptions. For example, baby picture requests and accompanying biographical writing activities may distinguish between normal life/birth history and those many international adoptees have experienced, where the only baby pictures they may have reflect infancy in an orphanage, prior to life with a family. ${ }^{11}$ Assignments such as life histories, life timelines beginning from birth, family histories, particular types of autobiographies, all-about-me books, and star of the day/week activities may also contain hidden assumptions that all children share a similar "normative narrative" (Carrington, 2002) of their birth and genealogical history, and of their family composition. When familial diversity is ignored within language and literacy classrooms and assumptions such as those of genealogical ideology remain uninterrogated, children who do not fit into the dominant family structure may find themselves surrounded by curricula and literature that bear little resemblance to their own lives. It seems classrooms have moved very little from the families portrayed in the basal readers of the past, the families of Dick and Jane or Janet and John that I read about in my 1960s childhood. In current instructional series, while the character equivalents of Janet and John might now be racially or ethnically diverse, they are still likely to be represented as members of two-parent, biological families.

Even if language arts teachers are alert to the need to include alternative family formations, finding suitable literature resources can present challenges, as Satz (2007) has noted. In gathering my own collection of children's books for my daughters and for my academic research in diversity, I often encounter bookstores or public libraries where, on the shelves, there are few, if any, children's books on adoption or that include adopted characters, or that address different forms of family diversity, although books that address racial and cultural diversity are now increasingly accessible and will often be prominently 
displayed. Perhaps this availability issue may also partly explain why the parents in my study also noted a lack of books that address family diversity or adoption within their children's schools. With limited funds and limited time, teachers and school librarians may not be aware that they need to dig deeper to find resources that address family diversity. ${ }^{12}$ While finding good books that address different family compositions can take more effort, in recent years I have witnessed these resources increasing and more choices are now available (see Sample Children's Literature Resources listed at the end of my reference section for several examples). However, I still notice that my children rarely encounter such books in their local libraries, school libraries or classrooms, aside from the ones I provide.

While children of new families increasingly populate Canadian language arts classrooms, the challenges outlined suggest students may often encounter old classrooms rather than new ones. Such demographic changes do not automatically result in changes in practices and classroom materials. In writing about the difficulty of getting practitioners to adopt new practices from emerging research in the medical field, Stephen Genius (2009) refers to what he labels "professional lethargy":

Medical history is replete with examples where sluggish dissemination and adoption of innovation has extracted a heavy toll. It was not until his contemporaries died and a new generation of physicians emerged that Semmelweis' hand washing intervention to prevent transmission of organisms and puerperal sepsis was implemented. (p. 12)

Education seems to suffer from a similar disorder, and though the consequences of this lethargy may not exact consequences that are quite so dire, I would suggest that there is also a "heavy toll" for the students who experience exclusion when societal change is ignored.

Finding Diversity: New Families, New Literacies, New Possibilities Today we answer the question, Can Elmo see all kinds of families? (Elmo's World, 2004)

[Within] the shift away from 'traditional' family is that increasingly we are being moulded into the kind of habitus that mitigates towards fluid social formations, towards a different lived experience of family.

Like subjectivity, the ways in which people inhabit family and/or interethnicity is mediated by time and place. That is, every family experiences itself in site-specific ways. This is not new. However, what is new is that we are no longer bound by ideological blinkers to expect to see the nuclear family narrative objectified in day-to-day life (Carrington, 2002, p. 141).

In the span of my adoptive families/diversity project, I have continued to witness many areas of strength within participating families, especially in regards to advocacy for their children at school. With relatively few resources that sensitively address the needs of adopted children available 11 to educators, adoptive parents themselves take on the responsibility to alert classroom teachers and schools and provide additional information and resources in response to curricula, activities, and texts that may pose problems. 
Typically, the demographic of parents who adopt internationally have a number of similarities. Parents tend to be older (as mentioned by several participants in their self-descriptions ${ }^{13}$ ), relatively affluent (parents can afford the expensive international adoption process and have an income level that would have been approved within a homestudy), and are familiar with both scrutiny (through the homestudy and agency processes) and the requirements of dealing with sometimes frustrating bureaucracies. The majority of parents in my study were also university educated. Whereas other minority parent groups (e.g. recent immigrants, refugees, single parents in low income groups) may be reluctant or less able to intervene or make a fuss at school when a child experiences exclusion or discrimination, the international adoption process itself requires a certain level of competence in dealing with institutions, a willingness to face obstacles, and presumed ability (as determined within the homestudy process) to advocate for a child who will have unique needs. At least to the point that parents in my study self-reported, it seems that this group of parents has become a significant force in provoking changes at the schools their children attend and in challenging practices and curriculum materials that prove troublesome for their children.

Parents of internationally adopted children have also tapped into external resources in terms of "shaping and sustaining a sense of kinship and community beyond the family" (Volkman, 2003, p. 33). Organizations that link families of adopted children (e.g. FCC: Families with Children from China; IAFA: the Alberta International Adoption Families Association) create opportunities for sharing challenges and ideas, including those relating to schooling. However, another powerful influence for adoptive families in creating community, telling their stories, and sharing and soliciting information is the plethora of Internet discussion groups now available. As Volkman (2003) points out "both the Internet and adoption from China began to grow at approximately the same time" (p. 34), and online communities have become a powerful tool for adoptive families. For families adopting internationally, the advantages of electronic media are clear when families who may be in a small minority where they live are able to connect to hundreds or even thousands of other similar families worldwide. Parents have the option of joining both very broad-based groups and smaller groups that address specific commonalities or interests. ${ }^{14}$ Adoptive families have generated hundreds of discussion groups, blogs, Facebook pages, and Twitter sites, facilitating vast social networks and outpacing what is available through conventional print options. While in the early days of adoption related blogs, families used blogging as an accessible method for sharing their experiences of adoption and for documenting adoption travel, these tools are being used for a wider range of communication and increasingly, even younger adoptees are using such spaces to share their views or experiences. ${ }^{15}$

Many families initially participate in online communities for support and to research the complex world of international adoption as they begin the adoption process. Later, online groups are used to address particular concerns as families return to Canada with their child, or as a means to finding resources for their children, such as searching out adoption related books and culturally representative play materials. Discussions sometimes lead to political action such as efforts to persuade the Canadian government to grant automatic citizenship for internationally adopted children, or to problem solve (e.g. developing solutions for families left in limbo with the bankruptcy of the Canadian adoption agency, Imagine; lobbying politicians to fast track in process adoptions in Haiti 
after the earthquake).

Both adoptive parents and older adoptees have used online resources to speak out about movies or media articles that show bias against adoptees. For example, the 2009 movie Orphan was critiqued as presenting negative adoption stereotypes, with protests of the language used in the movie trailer ("It must be difficult to love an adopted child as much as your own"). Warner Brothers changed the trailer voice over, in response (see, SFGate, 2009, “Adoption groups angry with 'Orphan' stereotypes"). Twice the Rice (http://twicetherice.wordpress.com/) and a number of other blogs written by adult adoptees critiqued the decision of the New York Times not to include the voices of adult transracial adoptees in their month long series on adoption entitled Relative Choices: Adoption and the American Family (http://relativechoices.blogs.nytimes.com/). Within adoption communities such posts or discussions "go viral" very quickly as members post them on discussion boards or link within their blogs or Facebook pages. ${ }^{16}$

As internationally adopted children grow older and deal with more complex issues, online parent discussions shift to address issues of language education, racism, and school related issues. Such discussions are particularly suited to collective sharing of such anecdotes and responses often include strategies that other parents have used to deal with similar concerns. In a number of chat groups, files are compiled that include documents such as sample letters to the teacher providing adoption information and requests to be informed about particular studies, alternatives to activities such as creating family trees (frequently a stumbling point for adopted children and diverse families), and links to resources for schools. If the presence of adult and older adoptees on Internet and digital technologies is any indication, my children and those in my study will soon follow, particularly if Roger's (2003) notion of "family literacy as apprenticeship" is heeded, and children witness and learn the digital literacy strategies being used by their parents.

What is particularly intriguing to me, as a literacy educator and researcher, is how new families such as those in the international adoption community have used new literacies such as those of the Internet and electronic media, for learning, communication, and self-expression. As Luke and Carrington (2002) state, "New capitalism has created the conditions for the deployment of new and hybridized identities and the emergence of new literate practices" (p. 236). The New London Group (1996), in theorizing "a pedagogy of multiliteracies", suggests that student "cultural and subcultural diversity" ( $p$. 61) and changing technologies require broader modes of representation than have been historically used in classrooms. These and other new literacy researchers understand that part of the "new" in new literacies is the valuing of sociocultural contexts and acknowledging that practices are always combined with such contexts (Lankshear \& Knobel, 2007). For example, Carrington and Luke (2003) present the case of "Eve", a child living in a busy single parent divorced family. Eve participates actively in electronic media, more likely to be web surfing rather than listening to bedtime stories and frequently writing emails to her mother with whom she does not reside. As Carrington and Luke point out, Eve's context (living apart from her mother and being cared for by a busy working father) is such that electronic technologies meet family needs in ways that print technologies do not. Similarly, the new families of international adoption often use new literacies because they are a particularly good fit for global families, where parents journey thousands of miles to meet their children, and birth countries continue to occupy 
a place in family lives and stories. New literacies make it possible for similar families and children to connect when they are located at a distance from one another. Adoptive families are able to develop or maintain links that may be important to their children's sense of personal history and cultural identity, through such things as continuing correspondence with other families in adoption travel groups or the families of children adopted from the same orphanage, and/or remaining in email contact with a child's foster family or orphanage staff in their birth country. The Internet also provides additional information to add to international adoptees' often too slim early histories-for example, websites where it is possible to find the daily weather report of the region where children were born or lived prior to adoption. Increasingly, school age international adoptees are themselves joining online adoption communities and creating their own blogs.

What these virtual and electronic texts provide for diverse families is the experience of being less isolated in the world, as people who, in such online collectives, do not need to define or explain the structures or histories of their families. As my daughters grow older, while still enjoying the books they own that feature adoption, adopted characters, or families like ours, there are times when they prefer familiar virtual texts: the websites or blogs connected with their orphanages, webpages of other adoptive families, and our own family's blogs, including those they plan and create. In the weave of texts in their lives, these new literacy artifacts also have an important place. Mackey (2009) refers to text ${ }^{17}$ in the digital era as "porous, hybrid, slippery, and unfinished" ( $p$. 3 ), and as I read her descriptions of the fuzziness and permeable boundaries of contemporary digital communication technologies, the language strikes me as familiar, words that have been used to describe the identities of transracial internationally adopted children, who cannot be summed up neatly. Indeed, within my study, although all the children were of elementary school age, with the majority being in primary grades, the parents reported that their children were beginning to grapple with the notion that their identities were more complex than those of their non-adopted peers, and while the children were not using words like "hybridity", their reported descriptions were often just that: "Canadian and Chinese", "Vietnamese and Canadian and adopted". If transracial adult adoptees ${ }^{18}$ who are publishing online or in print texts provide any indication, questions of the fuzziness and hybridity of adoptee identity will only continue as the current international adoptee population matures (see for example, Hübinette, 2007). ${ }^{19}$

It is somewhat ironic that, while in language arts classrooms it is fairly unusual to find books and materials that portray different families like ours, adoptive families tend to be reflected far more actively online or in the popular media, in occasional television advertisements, popular series (e.g. episodes of Law and Order, ER, The Simpsons, although often such episodes may contain stereotypes or misinformation), or in the news. For children, while Sesame Street has long been one of few children's programs to broach the topic of family diversity, there are signs that this is beginning to change, with newer children's series such as Rolie Polie Olie, Nihao Kai-Lan, and Miss Spider featuring integrated storylines about diverse families or characters who were adopted. But the fact remains, far less often does adoption or family diversity show up in school or classroom libraries.

\section{Where Do We Go from Here?}

While this article critiques some gaps in regards to how family difference is 
addressed in schools, it is also clear that there is an important role for language and literacy educators in providing leadership and modeling systemic change in embracing children from new families in contemporary classrooms. The work of critical literacy, multiliteracies, and digital technologies can provide valuable tools for analysis, critique, and representation in response to changing classrooms. However, for such possibilities to occur, new awareness is needed. As the parents in my study reported, generally most problems their children experienced emerged as a result of educators being ill-informed about adoption or other family differences. The problematic assignments or curriculum structures all had the possibility to be more inclusive and positive experiences for students if teachers had been aware of implicit biases (about birth history, family background etc.) and, instead, framed troublesome language arts assignments to be more open-ended. Thus, it is important to include some specific recommendations for educators, to avoid the pitfalls and problems recounted by the families in my study.

\section{Language}

One of the ways that bias can be revealed is in language. While, currently, most teachers would never intentionally use racist language in the classroom, the same cannot be said in terms of language related to adoption or family structure. One word that poses particular problems for adoptive families is the word "real". As one parent recounted: "we have been asked in the presence of our kids (both of whom have ears the last time I checked) if they are 'real' siblings".

Adoption creates real family relationships, and adoptive families and children have difficulty when those relationships are not equally valued. Klatzin (2001) relates the story of her six-year-old daughter's experience in grade one when the teacher read a book about adoption and another child in the class had asked if the two adopted girls were real sisters: "And the teacher had answered, 'They're kind of sisters.' It's possible that no one except my daughter picked up on the subtext of that answer.... She heard that the teacher wasn't sure just how 'real' those sisters were" (p. 2).

In adoptive families, sticking with plain relational terms (e.g., mom, dad, sister, brother) usually avoids such problems. One family in my study, parents of a biological child and an adopted child, also expressed frustration with people who continued to differentiate between their two children as "your own child and the adopted one". Other parents expressed concern about how the word "adopted" can be used by others ${ }^{20}$ as a condition of identity rather than an event that took place in the past (e.g. "She is adopted" vs. "She was adopted"). There are several good resources developed specifically for teachers that address the topic of "adoption friendly" language (e.g., Hillborn, 2005; Wood \& Ng, 2001), and many online resources that are easily accessible (e.g. a Google search of terms such as "positive adoption language", "adoption friendly language" and "respectful adoption language" will find dozens of links from adoption related websites).

\section{Assumptions about "Universally Shared" Information in Assignments}

As mentioned earlier, the types of school assignments that can pose problems for adopted children tend to share the incorrect assumption that all children experience a similar life (and birth) history, or present other aspects of genetic ideology. Within language arts classrooms, personal or biographical writing assignments are commonly assigned, and these are often linked to curriculum outcomes. As addressed earlier, when 
diversity was ignored or neglected in such projects, the children and families in my study experienced difficulties and dilemmas.

Mitchell (2007) writes about ten year old Maria, who had a writing project that asked many specific questions about her early life, including where she was born and what her first weeks home from the hospital were like. She reports:

Maria was very upset by this project; she and her mother, Barbara, could only answer 5 of the 17 questions.... Maria's teacher was aware that Maria had been adopted as a preschooler, but it didn't occur to him that this assignment would be traumatic for her. (p. 3)

For children whose life experience is different from their peers (and this group goes beyond adopted children) such assignments provide yet another reminder of how they are not like their classmates, and present troubling dilemmas in regards to requirements to share private and even traumatic information in the public forum of the classroom. As Mitchell suggests (2007), simply providing choices or broadening the assignment can eliminate the potential difficulties. For example, allowing students to write about themselves in the past in the time frame of their choosing, creating a more imaginative writing activity (e.g. "When I was a baby, I think I was__ " and including self-portraits of how they imagined they looked at a younger age), or presenting several different options for biographical writing such as: "When I was little", "Someone special in my life", or "My favourite activity". Turner-Vorbeck (2005) suggests using inclusive alternatives such as the ME Poem where students can develop "descriptive statements about themselves, their interests, and their lives, including family members" (p. 8), using open ended criteria such as several adjectives to describe themselves, lists of interests.

Awareness of What and Who are Being Represented (and Who May not be) in Classroom Texts

As suggested earlier, some children's books present an underlying message (e.g., Satz, 2007) that present a genealogical bias (i.e. families should resemble one another). Just as contemporary teachers and librarians are alert to issues of gender or racial bias in children's books, they should also be looking critically at how families are being presented, as well as working to select books that include adoptive and other diverse family models or characters. For example, as an alternative to Are You My Mother,? Chih-Yuan Chen's (2007) picture book Guji Guji presents the engaging story of a crocodile who hatches within a duck family and is loved for his differences and saves the day using his own special abilities.

Adoptive and other diverse families likely have more commonalities than differences when compared with other families, especially in regards to the details of daily existence that are an integral part of family life. Such details are the focus of several recently published children's books that address family diversity, which, while mentioning differences and uniqueness 
of some families, centre on family practices and shared experiences. And Tango Makes Three (Richardson, 2005) the true story of two male New York City Central Park penguins who raised a baby penguin together concludes with the following words: "they snuggled together and like all the other penguins in the penguin house, and all the other animals in the zoo, and all the families in the big city around them, they went to sleep" ( $p$. 28).

Parr's (2007) We Belong Together: A Book about Adoption and Families discusses some of the reasons for adoption and typical practices that families enjoy together.

Similarly, Parr's The Family Book and It's Okay to Be Different present positive adoption portrayals alongside other text examples. Of course, in addition to examining classroom and library texts for bias, and including a wider selection of texts that feature diverse families, teachers can also encourage students to read critically, going beyond gender and racial stereotypes and adding family stereotypes to other issues when addressing critical literacy in the language arts classroom.

\section{Making Use of Digital and Electronic Representations and Opportunities}

As previously outlined, digital and electronic technologies present opportunities for students that may be less present in print texts. Research assignments that allow for student input and choice, and the use of, for example, blogs, digital video, and podcasts or webcasts, for students to develop their own projects, can provide ways for students to share their own stories and see themselves reflected back in the larger world of texts. However, just as print-based assignments can contain bias, digital assignments also need to be crafted with sensitivity and awareness in regards to children's individual circumstances. As Klatzin (2001) suggests, adopted children prefer to be participants in diversity-based activities or discussions rather than the subjects of them, unless they have specifically chosen to share adoption related details.

\section{Last Words}

In concluding, I return to my beginning example. In my daughters' old preschool favourite, Elmo's World (2004) video, Families, Mail, and Bathtime, families are shown to exist in their shared details and practices, and their caring for one another, rather than who they are, how they are related, where they have come from, or the circumstances in which they live. Perhaps a similar approach might offer possibilities and alternatives for framing discussions and assignments related to families in language arts classrooms, to avoid the pitfalls and problems resulting from approaches that focus more on comparing, sorting, and measuring against genealogical or normative models.

On writing about familial love, Sumara (2002) questions the view that all families should be like the Dick and Jane families in basal readers or the families in the sixties sitcom worlds. Instead, he suggests that the experience of relation in families is more of "an inextricable quality" of existing together in a "shared world". He writes, "Love is organized by the small stories of lived experience, not by grand narratives" (pp. 107-108). Such "small stories" and details of daily existence are an integral part of family life. In schools, alternative frames and descriptions need to be put into use, those that go beyond 1960s assumptions and instead focus more on the practices, experiences, and daily details that make people into families, and which are often the focus of the online texts that have been taken up by other kinds of families. 
My hope for my own children as they go to school is that perhaps this will be the year that they will find themselves in the texts on their classroom or library shelves and the year I will not need to explain to their teachers why particular assignments or activities pose problems, because our kind of family will be recognized, too.

Notes

1 In my definition of "texts", I include both electronic and popular media texts, alongside literary and curricular texts.

2 In an earlier article (see Laidlaw, 2006) I address some of the broader curriculum areas within this research project.

${ }^{3}$ Over the past few years Sesame Street programming has extended the series to develop components of the show now presented separately on a number of children's television channels. (e.g. "Global Grover", "Elmo's World", "The Adventures of Bert and Ernie" etc.)

4 "Elmo's World clips are featured within the Sesame Street television program as well as being available independently, as videos for purchase, and within the Canadian Treehouse Channel.

5 Statistically, this would be true, with Canadian intercountry adoptions in recent years acknowledged at close to or fewer than 2000 per year to date, although Canadian Citizenship and Immigration has not yet released 2008 numbers (see Hilborn, 2009; and Citizenship and Immigration Canada, 2009).

6 At the time of my survey, China had been a dominant "sending country" since the mid 1990s and thus, there were growing numbers of Chinese adoptees within the school system. While I hoped to also include some of the families who had adopted from other countries now increasing in international adoptions (e.g. Ethiopia, South Africa, etc.) at the time of the survey relatively few of these children were school-aged.

7 It is important to note that non White parents also adopt internationally, and I made a number of attempts to include several Canadian-Chinese parents as I was aware of a growing number of adoptive parents in this category who had adopted from China.

None of these families chose to participate, so it may have been that they felt less need to convey their child's experiences of schooling because they were not dealing with the same issues around racial difference. Similarly, while I invited parents from a wide array of international adoption communities, I received no response from Canadian families who had adopted Caucasian children internationally (e.g. Russia, Kazakhstan) who were racially similar to their adoptive parents.

${ }^{8}$ Recently with adoptions from China (a significant sending country) fewer in number than in previous years, and with the China Centre for Adoption Affairs implementing more restrictions on adoptive families as well as increasing wait times due to fewer referrals, Canadian families are increasingly choosing to adopt from multiple countries, with, for example, a first child adopted from China and second from Ethiopia or Vietnam. While no statistics are currently available, such families are an increasing presence at local international adoption gatherings and within the membership of adoption related online discussion groups and forums, as are 
non-White adoptive parents.

9 Adoptive parents most often are outsiders to their child's birth culture, so their supportive actions, however well intentioned, tend to present more of a tourist perspective (e.g. "dragons and chopsticks") than those that might be more authentic.

10 Rothman (2005) critiques the Sesame Street song "One of These Things (Is Not Like the Others)", mentioning that the song is the target of frequent complaint by older adoptees, who recounted feeling like they were just like the object or person who doesn't belong:

Three of these things belong together

Three of these things are kind of the same

Can you guess which one of these doesn't belong here?

Now its time to play our game,

Time to play our game.

11 This past year one of my daughters experienced a request to bring in a baby photo for a school activity, and while the activity was presented in an open ended manner with options for bringing in older photos and no pressure to conform to a particular standard, because many of her classmates shared newborn or young baby photos she was very clear that she did not wish to participate without a similar photo (which we do not have, aside from that of an abandonment notice published in a Chinese Newspaper). In the end, she elected not to participate rather than sharing a photo different from those of her friends.

12 In gathering my own books, I have relied on the book collections available at or publicized by adoption agencies and organizations to learn about new titles and I have also become acquainted with smaller publishing houses that focus on adoption and diversity titles. My participants, similarly, often mentioned collecting books recommended by adoption practitioners.

13 Sending countries have upper and lower ages limits for adopting parents. For example, China requires that adoptive parents both be over 30 years old, and within my respondents who had adopted from China, most were over 40.

14 Some examples of such groups: A-P-C (A-Parents China), a large American listserve for adoptive and prospective adoptive parents; I-A-T

(International-Adopt-Talk, a site which often explores controversial issues); SingleWithTwo (a group for single parents who have adopted at least two children).

15 For example, I have followed a private blog where a preteen journalled her experience of spending a summer in her birth country.

16 Within the group of my parent participants, while I did not ask direct questions about their technology usage in relation to adoption, the majority of my participants learned about my study through various online adoption related groups, and most chose to participate, at least in part, via a series of electronic exchanges and discussions.

17 Mackey is specifically addressing literature, but the qualities she describes also seem suited to other forms of digital text.

18 In recent years, adults adopted from Korea or Vietnam to North America have become more vocal about their experiences and sense of identity and often present a cautionary tale of the consequences for adoptive parents if they ignore issues of race, 
culture, and adoption.

19 As well, there are many adult adoptee authored blogs that address the topics of identity, race, culture and adoption, such as twicetherice.wordpress.com, harlowmonkey.typepad.com, loveisntenough.com

${ }^{20}$ While some adoptees do include adoption as a part of their identity, the general consensus within adoption communities is that this is a descriptive choice to be made by the individual rather than by others. This is similar to how other labels or descriptors have changed in the past (e.g., referring to "a child with Down's syndrome" rather than "the Down's syndrome girl").

\section{References}

Alberta Children's Services. (2008). Summary of adoption in Alberta statistics (April 1, 2007- March 31, 2008). Retrieved August 10, 2009, from http://www.child.alberta.ca/home/608.cfm.

Anderson, H.C. (1945). The ugly duckling. Fairytales. New York: Grosset \& Dunlap.

Behar, R. (1996). The vulnerable observer: Anthropology that breaks your heart. Boston: Beacon Press.

Cannon, J. (1993). Stellaluna. Toronto: Harcourt.

Citizenship and Immigration Canada. (2009). International adoption. Retrieved July 9, 2009, from http://www.cic.gc.ca/english/immigrate/adoption/index.asp

Carrington, V. (2002). New times: New families. Dordrecht, The Netherlands: Kluwer.

Carrington, V., \& Luke, A. (2003). Reading, homes and families: From postmodern to modern? In A van Kleeck, S.A. Stahl, \& E.B. Bower (Eds.), On reading to children: Parents and teachers (pp. 221-241). Mahwah, N.J.: Erlbaum.

CBC News. (June 2, 2009). "Alberta passes law allowing parents to pull kids out of class: Written notice required when sex, sexual orientation, religion are covered." Retrieved July 9, 2009, from http://www.cbc.ca/canada/story/2009/06/02/alberta-human-rights-school-gay-edu cation-law.html

Clifford, J., \& Marcus, G. (Eds.). (1986). Writing culture: The poetics and politics of ethnography. Los Angeles: University of California Press.

Diaz, C., \& Makin, L. (2002). Literacy as a social practice. In L. Makin \& C. Diaz. Literacies in early childhood (pp. 3-13). Sidney: MacLennan \& Petty.

Eastman, P.D. (1960). Are you my mother? New York: Random House.

Elmo's World [video]. (2004). Families, mail and bath time! Toronto: Sesame Workshop.

Gee, J. (2001) A sociocultural perspective on early literacy development. In S.B. Neuman \&

D.K. Dickinson (Eds.). Handbook of early literacy research (pp. 30-42). New York: the Guilford Press.

Geertz, C. (1988). Work and lives: Anthropologist as author. Stanford, CA: Stanford University Press.

Genius, S., Schwalfenberg, G., Hiltz, M., \& Vaselenak, S. (2009). Vitamin D status of 
clinical practice populations at higher latitudes: Analysis and applications.

International Journal of Environmental Research and Public Health, 6, 151-173.

Gregory, A., \& Snow-Gerono, J.L. (2006). Imagining alternatives: Family constructs, stories of early childhood, and making ready for children. Paper presented at the annual meeting of the American Educational Research Association, San Francisco, CA.

Heath, S.B. (1983). Ways with words: Language, life and work in communities and classrooms. Cambridge, MA: Cambridge University Press.

Hübinette, T. (2007). Disembedded and free-floating bodies out of place and out of control: Examining the borderline existence of adopted Koreans. Adoption and Culture: The Interdisciplinary Journal of the Alliance for the Study of Adoption and Culture, 1(1): 129-162.

Hilborn, R. (2009). China still the Canadian favourite for intercountry adoption: 2007 statistics. Family Helper: Adoption News Central. Retrieved July 9, 2009, from http://www.familyhelper.net/news/090106stats07.htm

Hunt, E. (2003). Out of the shadows: Adoptive families seek to transform classroom strategies. Teaching Tolerance Magazine, 24, Fall. Retrieved July 9, 2009 from http://www.tolerance.org/magazine/number-24-fall-2003/out-shadows

Klatzin, A. (2001). Reprint. How I explained adoption to the $1^{\text {st }}$ Grade. Adoptive Families Magazine, March/April: 1-3.

Kotler, J. A., Cohen, D., \& Truglio, R. T. (2007). Sesame Street U.S.A: Research from season 37. Abstract. Paper presented at the annual meeting of the International Communication Association, TBA, San Francisco, CA. Retrieved July 2, 2009, from http://www.allacademic.com/metap_mla_apa_research_citation/1/7/0/5/5/p17055 2_index.html

Laidlaw, L. (2006, Winter). Learning to "do family" differently: Towards more complex notions of family, culture, and schooling. Journal of the Canadian Association for Curriculum Studies, 4 (2), 41-54. Retrieved January 10, 2010, from http://www.csse.ca/CACS/JCACS/V4N2/PDFContent/3._laidlaw_4.2_jcacs_ formatted.pdf

Lankshear, C., \& Knobel, M. (2007). Sampling the "new" in new literacies. In M. Knobel \& C. Lankshear, C. (Eds.), A new literacies sampler (pp. 1-24). New York: Peter Lang.

Luke, A., \& Carrington, V. (2003). Globalisation, literacy, curriculum practice. In T. Grainger (Ed.). The Routledge Falmer reader in language and literacy (pp. 52-66). New York: Routledge/Falmer.

Mackey, M. (2009). Literature in a new era: Porous, hybrid, slippery, and unfinished. In S. Peterson, D. Booth, \& C. Jupiter (Eds.). Books, media and the Internet (pp. 3-10). Winnipeg: Portage \& Main Press.

Mitchell, C. (2007). Adoption awareness in school assignments: A guide for parents and educators. Electronic brochure. Retrieved January 10, 2010, from http://www.tapestrybooks.com

Parr, T. (2007). We belong together: A book about adoption and families. New York: 
Little, Brown and Company.

Patton, S. (2000). Birth marks: Transracial adoption in contemporary America. New York: New York University Press.

Pertman, A. (2000). Adoption nation: How the adoption revolution is transforming American culture. Berkeley: University of California Press.

Policy-relevant Research on Immigration and Settlement-Relevant for Whom? (2005). A working document: The strategic workshop on immigrant women making place in Canadian cities. Retrieved August 9, 2009 from http://genderimmigration.inrs-ucs.uquebec.ca/.

Richardson, L. (1997). Fields of play: Constructing an academic life. New Brunswick, NJ: Rutgers University Press.

Richardson, J. (2005). And Tango makes three. Toronto: Simon \& Schuster.

Rogers, R. (2003). A critical discourse analysis of family literacy practices: Power in and out of print. Mahwah, NJ: Lawrence Erlbaum Associates.

Rothman, B. K. (2005). Weaving a family: Untangling race and adoption. Boston: Beacon Press.

Satz, M. (2007). Finding oneself: Images of adoption in children's fiction. Adoption and Culture:_The Interdisciplinary Journal of the Alliance for the Study of Adoption and Culture, 1(1): 163-186.

SF Gate (2009, July 17). Adoption groups angry with 'Orphan' stereotypes. San Francisco Chronicle, Friday, July 17, 2009. Retrieved August 7, 2009 http://www.sfgate.com/cgi-bin/article.cgi?f=/c/a/2009/07/16/MV1N18L5U1.DTL

Simon, R. J., \& Altstein, H. (2000). Adoption across borders: Serving the children in transracial and intercountry adoptions. Lanham, MD: Rowman \& Littlefield.

Statistics Canada. (2002). Profile of Canadian families and households: Diversification continues, 2001 census (Analysis Series). (Detailed analysis of 2001 census population data). Catalogue No. 96F0030XIE2001003. Released, Oct. 22, 2002. Retrieved September 10, 2003 from http://www.statcan.ca/english/ IPS/Data/96F0030XIE2001003.htm

Statistics Canada. (2007). Family portrait: Continuity and change in Canadian families and households in 2006, 2006 census. (Detailed analysis of 2006 census population data). Catalogue No. 97-553-XIE. Retrieved August 9, 2009 from http://www12.statcan.ca/census-recensement/2006/as-sa/97-553/index-eng.cfm.

Sumara, D.J. (2002). Why reading literature in school still matters: Imagination, interpretation, insight. Mahwah, NJ: Erlbaum Associates.

Turner-Vorbeck, T.A. (2005). Expanding multicultural education to include family diversity. Multicultural Education, 13(2), 6-10.

Turner-Vorbeck, T.A. (2005). Representations of family in curriculum: A post-structural analysis. In C. Cherryholmes, E. Heilman, \& A. Segall (Eds.), Social studies-The next generation: Researching social studies in the postmodern. New York: Peter Lang.

Volkman, T.A. (2003). Embodying Chinese culture: Transnational adoption in North America. Social Text 74, 21(1), 29-55.

Wood, L., \& Ng, N. (2001). Eds. Adoption and the schools. Palo Alto, CA: Families Adopting in Response. 


\section{Blogs Cited}

http://harlowmonkey.typepad.com

http://loveisntenough.com

http://relativechoices.blogs.nytimes.com/

http://twicetherice.wordpress.com/

\section{Diversity Resources}

Hilborn, R. (2005). Teacher's Guide to Adoption (2nd ed.).

Laidlaw, L. (2007). Creating an inclusive language arts classroom: Addressing diversity. [online]. http://addressingdiversity.blogspot.com/

MacLeod, J., \& MaCrae, S. (2006). (Eds.). Adoption parenting. Warren, NJ:

EMKPress.

Schoettle, M. (2003). S.A.F.E. at school: A Manual for teachers and counselors. The Center for Adoption Support and Education.

Schoettle, M. (2000). W.I.S.E. Up Powerbook. The Center for Adoption Support and Education.

\section{Sample Recommended Children's Literature Resources}

Bauer, M. (2007). A mama for Owen. Toronto: Simon \& Schuster.

Chen, C. (2007). Guji Guji. La Jolla, CA: Kane Miller.

de Haan, L., \& Nijland, S. (2000). King and king. Toronto: Tricycle Press.

Fry. Y.Y. (2001). Kids like me in China. St. Paul, MN: Yeong \& Yeong.

Kasza, K. (1992). A mother for Choco. New York: G.P. Putnam's Sons.

Katz, K. (1997). Over the moon: An adoption tale. New York: Henry Holt \& Company.

Kerley, B. (2005). You and me together: Moms, dads, and kids around the world. Washington, DC: National Geographic.

Kitz, C. (2003). I don't have your eyes. Warren, NJ: EMK Press.

Kitz, C. (2003). We see the moon. Warren, NJ: EMK Press.

Moore-Mallinos, J. (2007). We are adopted. New York: Barron's.

Parr, T. (2003). The family book. New York: Little, Brown and Company.

Parr, T. (2007). We belong together: A book about adoption and families. New York:

Little, Brown and Company.

Parr, T. (2009). It's okay to be different. New York: Little, Brown and Company.

Say, A. (1997). Allison. Boston: Houghton Mifflin.

Young, E. (2006). My mei mei. New York: Philomel Books. 